\title{
Matching Students' Dominant Intelligences with their Fields of Specialization: Did Students Select the Right Specialization?
}

\author{
Faten Sulaiman Saleh \\ High Health Council (HHC) \\ drfatensulaiman@yahoo.com
}

Received :23/12/2020

Accepted :27/6/2021

\begin{abstract}
Accreditation is a fundamental part in primary healthcare (PHC) systems. The purpose behind this paper is to review the literature and track down the most appropriate PHC accreditation models and norms, around the world, and to set up a complete and fair outline from looking at these models.

Finding that it is less likely to be independent, and more likely to be associated with government for the accreditation programs in developing countries, where they are distinguishable from those of developed countries, the differences between countries and agencies relate to the inclusion of patients/users, managers, patient or advocacy organizations, academic organizations and professional colleges. This review has identified that the most potential comprehensive reference program or model for the development of nation accreditation programs is the JCAHO program.
\end{abstract}

Keywords: Healthcare, Accreditation Systems, Jordan, Ministry of Health, Quality.

\section{Introduction and Background}

Healthcare services are vital components of societies, to which many financial and social resources are undoubtedly devoted. As well as, the quality of healthcare organizations (HCOs) is also very significant for many stakeholders, including governments, nongovernmental HCOs and patient-centered organizations.

This paper intends to discuss; based on a review of the international scientific literature, accreditation of the healthcare organizations in different countries. It also discusses the accreditation development in in the Jordanian context.

Indeed, healthcare services are a constant concern. Improving quality, from any perspective, is both a challenge and a necessity; for it requires a change in healthcare organizations and should involve the design of plans and strategies, the development of health professionals, and better outcomes. Only if the improvement has an impact on these three aspects, we can really refer to an improvement in healthcare 18.

The most critical component of healthcare systems is ensuring quality; as it represents the level to which healthcare services follow recent professional expertise, fulfill the needs and expectations of clients and improve the possibility of attaining anticipated health results. It is not enough for patients to have access to a healthcare facility; they always want to get care that is reliable in and consistent with the up-todate clinical standards 4334 .

Lately, the quality revolution that has been adopted by the service and manufacturing industries has expanded into the healthcare industry. The fundamental quality assurance and improvement theories, as well as the comprehensive quality management approaches of Total Quality Management (TQM) and Continuous Quality Improvement (CQI), are adopted in the day-to-day actions of HCOs all over the world 106049.

Governments and professional entities have adopted several assessment methods addressing quality in HCOs. Certification, accreditation, and licensure are still the most prominent methods. These approaches have common characteristics: All these approaches are based on external assessment against pre-determined standards, and have a shared objective of ensuring patients' safety and improving the healthcare quality. At the same time, these approaches differ in significant aspects: whether they are mandatory or voluntary; in the issuing; with respect to the accredited body; in the field of the standards; in the regularity with which assessment is performed; and in the adopted methodology of assessment. 1060. 
Since approaches aimed at assessing the structure of HCOs differ from those directed at individual practitioners. The assessment of HCOs quality may evaluate the inputs (e.g., policies, facilities, equipment, number of staff, training of staff), or outcomes (e.g., yearly performed procedures, incidence of infection, patient satisfaction, case fatality rates, continuity of care) for the HCO generally or for specific departments of it, however, not for specific practitioners inside the HCO 60.

The levels of clinical performance outcomes indicate the accreditation program's performance 7, the effectiveness of organizational structures, including HRM systems 14 or processes of care 22. The issue of defining if the participation in accreditation programs lead to continuous improvements, compliance to external standards, is still points of concern for stakeholders 2237.

The beginning of accreditation introduction was in the USA in 1917, used in some other countries such as Australia and Canada in 1950s before it spread worldwide in the 1990s. While accreditation originated largely in developed countries, national accreditation programs are newly introduced in many developing countries 4555 .

Also as notable in the developing countries, healthcare sector reforms have led to accelerated privatization and outsourcing of services and goods since the early 1990s. This is attributed to the interest in realizing a growth in efficiencies and quality improvements of both public and private sectors. A direct consequence was that there was a rapid progress in the adoption of External Quality Assessment (EQA) as a method for improving the quality of services rendered by HCOs in the developing countries 49.

\section{Methodology}

\section{Study design}

It is a comparative study, as the study conducted an international investigation of selected countries' accreditation systems. Some have well-established accreditation systems with long experiences, while some others have new established.

The researcher searched MEDLINE, Google Scholar, the Cochrane Library, Scopus, EBESCO using several keywords, including "Accreditation", "History of accreditation", "Development of accreditation" "Accreditation Programs", "Accreditation Agencies", "Healthcare services", "Healthcare quality",.

In addition, the researcher searched the websites of governmental entities and professional bodies. The researcher also searched the websites of the accreditation organizations operating in each country as well as other relevant organizations such as World Health Organization (WHO), ISQua, the World Bank, and USAID.

The Researcher's Contribution and Effort

A hundred and seventy five (175) abstracts screened and (144) articles reviewed in full, in addition to (46) papers found on websites of many national health agencies and healthcare accreditation agencies worldwide, as well as on ISQua.

\section{Literature Review \& Previous Studies Quality Improvement and Accreditation}

There is an increasing perception that continuous improvement of healthcare quality, in the public and private health sectors, may enhance health systems and drive better performance. Now, health services work in an atmosphere of rapid changes in social, economic, and technical areas. In the near future, such developments are likely to occur due to restructured economic and social policies, business globalization, and increased worldwide connectivity. In the past, several health systems have failed to determine the quality standard of client and systemic institutional care, resulting in an unsustainable cost increase. With a view to cost control and quality improvement, national health systems are under growing pressure because of restructuring of the health sector 51 .

Implementation programs for quality improvement in healthcare services driven by numerous factors, such as healthcare costs, number of adverse events, complexity of new technologies, and rapid global spread of transmissible diseases 52 .

Accreditation is considered as the most important single approach for improving the quality of health care systems. An accreditation system evaluates institutional resources periodically in order to confirm services quality based on formerly established standards and policies.

Accreditation aims to improve quality of healthcare services. The accreditation movement is gaining prominence due to Globalization, and especially the global expansion of trade in health services among world's countries. When applied properly, accreditation leads to strengthening the central leadership and guiding role of health authorities. 


\section{What is Accreditation in Healthcare?}

According to ACHC 1, accreditation is a process of assessment implemented by a recognized accreditation body allowing HCOs to prove their competence in meeting regulatory requirements and pre-established standards.

Montagu (2003) defined accreditation as "an external review of healthcare quality administered by an independent body and conducted by professional peers based on written and published standards with the aim of encouraging organizational development" 49.

Zeribi \& Marquez (2005) stated "accreditation is a formal process by which a recognized body - either governmental or nongovernmental - assesses and recognizes that a healthcare organization meets pre-established performance standards" 74 .

Swiers \& Haddock (2019) argued that Healthcare accreditation is an assessment of performance against pre-established standards. It gives a summary of performance against preestablished standards and the accredited organization is responsible for continual maintenance and enhancement of such performance 59.

The performance of a healthcare organization assessed against a group of standards developed by an accreditation agency in cooperation with the related stakeholders of the healthcare system. The accreditation program developed to assess practices, outcomes and structures, with the aim of constant improvements in the healthcare system 72 .

Accredited HCOs are required to carry out self-assessment against pre-determined standards, followed by an on-site survey. The goal of such survey is to confirm the self-assessment and contain delivery of documentation review, carrying out interviews with Self-Assessment Teams, patients/ purchasers, workforce and visiting the relevant organizations. Accreditation is an ongoing cyclical process through which a particular accreditation agency carries out assessment of the capability of the accredited $\mathrm{HCO}$ to perform its functions in keeping with pre-determined standards and applicable law 4.

Undoubtedly, the accreditation elements, such as the quality structure, standards, selfassessment process and on-site survey visit, help in improving quality, minimizing variability in practice, and reinforcing a culture of quality 48 .

\section{Benefits of Accreditation}

Accreditation is a trustworthy process employed for improving patient care and supporting a constructive culture and operative leadership in different countries and settings. It may lead to ongoing and structural improvements in quality within HCOs 3014315613.

In case the accreditation programs sufficiently carried out with accurate planning, good government support, and organizational commitment, they have the ability to increase the quality level of healthcare services in several developing countries. Accreditation program and other external assessment approaches are effective and reliable methods for improving healthcare in developing countries 49 .

According to 5, accreditation has numerous advantages, such as improving patient satisfaction, patient safety, quality of healthcare services, and status amongst HCOs.

Montagu (2003) argued that accreditation may play a key role in transmitting quality scientific evident to group and individual customers and in improving productivity in the health sector. If it is appropriately widespread, accreditation helps to improve the quality of the health sector through introducing information on quality and feedback on structures needed to realize quality 49 .

Accreditation system has Particular features making this system optimal for healthcare sector's stakeholders. In comparison to other comparable programs incorporated from other sectors of these features:

The assessment with a wide-ranging and interdisciplinary nature.

The assessment approach conforms the healthcare's uncommon features.

Improvement is a main objective of the assessment.

The assessment carried out by experienced professional surveyors in healthcare system 42 .

\section{The Origins and Development of Accreditation}

The first documented activity in the area of healthcare quality improvement dates back to 1854, during the Crimean War, when Florence Nightingale displayed descriptive statistical data that lead to improve standards of healthcare provided to the British troops in Turkey. She collected data on death rates among soldiers, and classified the death cases into three categories: (1) deaths due to preventable communicable diseases, (2) deaths caused by the patient's injuries suffered during combat ops, and (3) deaths resulted from all other causes combined. The data revealed that more than 18,000 soldiers admitted into military hospitals. Death rate 
among soldiers in field hospitals from avoidable complications is more than death rate in the battlefield.

Nightingale documented that implementation of improvements in advance of soldiers' admission to the hospital would lead to prevent thousands of excessive deaths 585738 .

US Sanitary Commission was founded in the spring of 1861 as a civilian organization recognized by the US government to provide medical services and to promote clean and healthy conditions in the Union volunteer forces during the American Civil War (1861-1865). It based on experiences from the Crimean War with the purpose of supporting hygienic and healthy conditions in the Union Army camps and hospitals 446857.

Quality standards for healthcare facilities were first developed in the United States in the "Minimum Standard for Hospitals" introduced by the American College of Surgeons in 1917. In 1947, the International Standards Organization (ISO) was created as result of increased global trade in manufactured goods. The ISO is the major actor in the field of development and publishing of international standards applied in international health sectors.

The Joint Commission on Accreditation of Health Organizations was created in 1951, followed, in 1957, by the Canadian Council on Accreditation. Governmental accreditation developed rapidly from the 1990s, usually administered by a ministry of health $(\mathrm{MoH})$ or a government agency. Hence, it argued that accreditation officially emerged in the U.S with the formation of the Joint Commission on Accreditation of Healthcare Organizations (JCAHO). The accreditation programs transferred to Canada in the 1960s, Australia in the 1970s and Europe in the 1980s, and spread all over the world in the 1990s 7324967.

Historically, accreditation aimed for voluntary, professional-driven ongoing quality improvement; after the mid-1990s, recent and existing accreditation programs have progressively developed to be tools for accountability to the public and to supervisory and funding bodies 54 .

Healthcare is in constant change in order to meet consumer needs and defined priorities. Changes in populations, technology and new research also combine to ensure that the care delivered will change, even if subtly, on a regular basis. Any tool for assuring and improving healthcare must therefore also be flexible and responsive. Recognized that accreditation may help or obstruct changes in healthcare and should be adaptive enough to ensure its contribution is positive 5914.

Accreditation standards have advanced in many aspects including quantity, quality, application, and setting. When these standards were first developed, they were mainly physical structure-standards of a hospital or of its workforce. Thereafter, process-oriented standards were introduced. Later, standards related to outcome were also developed. In the current list, there are process-related standards more than structural standards, and has contained other aspects such as rights and responsibilities of patients, leadership and ethics, and therefore moving away from distinct "departments" to functions.

The accreditation emphasis has also changed over time. The focus of accreditation was on hospitals, but now ambulatory care organizations, nursing homes, rehabilitation services, mental health services and home health organizations as well as managed care organizations are now accredited. As well as, accreditation activities not only carried out by the Joint Commission but other accreditation organizations that have begun forming for the same goal in other countries 72 .

\section{Accreditation - Global View}

Healthcare accreditation developed for over a century and was generally adopted in more than 70 countries around the world as an integral component of healthcare systems 1659 . Various health systems have implemented various methods to encourage quality improvement. Countries have adopted diverse methods for confirming quality and improving standards of healthcare facilities. Some countries, for instance, have left assuring the quality in healthcare to professional bodies and provider associations with slight detailed regulation 60274961.

Accreditation history of different countries shows development of a methodology that meets the requirements of governments, for both quality control and defining the health services standards and regulation 28 .

Accreditation standards established to be as measurable as possible. Such standards survey the several functions and elements carried out and owned by HCOs. A group of experts, connected directly to the HCO services, work annually on developing and updating these standards. These standards consequently introduced to survey the performance of $\mathrm{HCO}$ in the areas of care services provided by it 72 . 
Modern accreditation programs are being developed in Europe more than in any other part of the globe; they are transforming from the voluntary to profession-led models of USA, Canada, and Australia, where gradually developed programs are used to include the majority of HCOs, particularly hospitals. Conversely, earlier-developed European programs (Finland, Poland, Spain, Switzerland, and U.K.) have displayed slight or no progress in the past years. Since 1995, numerous new programs are developed; in general, such programs differ in purpose governance, and funding. Numerous of these programs are developed in smaller countries where few bodies will bear the foreseeable costs 54 .

As there are more than 70 healthcare accreditation bodies around the world, that set up or adopt standards, particularly for health services and organizations. The International Society for Quality in Health Care (ISQua) aimed at guiding and standardizing the establishment of these accrediting bodies and the standards they perform. ISQua performs the International Accreditation Program (IAP) for the certification or accreditation of standards against their standards 56.

Countries classified into developing and developed groups. Developing countries face many challenges compared with developed countries in providing quality healthcare. Aside from more resources, to improve the safety and quality of care, developing countries need political environments accompanied with appropriate capacity and effort to sustain organizations and services in support of healthcare provision; tools and infrastructure for healthcare quality and patient safety initiatives; and policies and actions to ensure improvement strategies 14.

Quality is not exclusive for developed countries. If countries are able to meet the expense of supplying any healthcare service, even the developing countries, they are required to provide such healthcare service with advantageous quality. The healthcare service with inadequate quality, in addition to be harmful, leads to dawdle invaluable resources that could otherwise be exploited in other vital factors of development aspects. Large sums of money spent as results of poor quality healthcare services, while such funds are exploited in many developmental aspects such as education, social services and infrastructure. In addition, the poor quality may also weaken the citizens' trust in the benefits of healthcare services 71 .
Healthcare accreditation organizations play a key role in improving health systems through stimulating and assist in the transformation standards of healthcare quality and safety into practice. It is more difficult for developing and underdeveloped countries, with considerably less resources and unstable political conditions, to retain the systems and institutions required for a thriving accreditation capacity 15 .

The development and implementation of accreditation programs in developing countries has been supported by several international bodies, such as: ISQua, WHO, JCAHO and JCI, and many funding agencies such as the USAID and the World Bank 4510.

There are many factors, categorized into external or internal factors, affect the successful and sustainable implementation of accreditation programs. External factors represent in the lack of legal status or early termination of financing by international funding bodies. Internal factors represented in a set of issues such as operational factors, management systems, program management, and stakeholder management 15 .

Healthcare accreditation programs may be voluntary at national or international level, or mandatory at national level. Both models share the principle of assessment of all divisions of the $\mathrm{HCO}$ by an external surveyor against preestablished and published standards that emphasize on quality and safety more than focusing on resources or outcomes 56 .

Accreditation organizations in developing and developed countries share a program model with mutual characteristics. They develop healthcare standards; subscribe members who perform self-assessment against those standards; employ, train, and administer surveyors; direct groups of surveyors to carry out assessment of healthcare organizations' progress against the standards; evaluate the report submitted by the survey teams; and, where acquired, award accreditation status for 3-5 years. Programs in Developing and under developed countries are similar in three features: funded by government, funding organization, or both, a large part of programs in developing and least developed countries declared offering numerous incentives for healthcare organizations to embolden them to participate in accreditation.

As $75 \%$ of programs in developing and least developed countries announced dealing with a small number of healthcare organizations, demonstrating significant possible ability for progress. 
The features recognize particular points of dissimilarities between programs of developing and least developed countries and those of developed countries corresponding to wider features related to: government, legal position, assessment of program, qualification of trainees, and employing arithmetical scoring in the decision to award accreditation 15.

Several countries have developed accreditation systems for healthcare organizations. Investigating global experiences in this field shows that the concept of accreditation witnessed advancement from applying a simple voluntary program with minimum standards of care towards the adoption of evidence-based policies and standards. One of the longest experiences at accreditation is found in developed countries have the longest experiences in the accreditation area, especially the USA which has established and advanced healthcare systems 274257. Country

Healthcare Accreditation: Summaries by

It is important to compare experienced accreditation systems Implementation of accreditation programs in different countries, to understand it better. A good amount of literature on healthcare accreditation programs is found.

Numerous accrediting bodies are established on the international level. Some of these bodies are funded by the government of a particular country, while others are private non-profit organizations supported by governments and prominent stakeholders of that healthcare system 72.

\section{Australia}

There are several accreditation agencies in Australia through which HCOs are able to gain accreditation against the Standards, of them:

The Australian Committee on Hospital Standards (ACHS)

ACHS is an independent non-profit accreditation agency in Australia created in 1974 by a group of professional colleges, purchaser, industry organizations, and government. ACHS's Mission is to "provide a partnership approach to continuous improvement tailored to the needs of individual services and health systems using its expertise in standards, accreditation, education and training" 4147239. ACHS has numerous quality improvement programs including Evaluation and Quality Improvement Program (EQuIP) which are designed to be used by all types of healthcare organizations. The ACHS has finalized the sixth edition of the EQuIP (EQuIP6) and adopted it since 2017239.

\section{Australian General Practice Accreditation Ltd (AGPAL)}

AGPAL is a non-profit company established in 1997 by representatives from all the industry's key organizations 1741. The AGPAL program is primarily employed for primary healthcare and comprises 48 standards developed by the Royal Australian College of General Practitioners. The RACGP standards outline the features of general practice promoting high-quality and safe comprehensive healthcare, including consideration to the provided services; the patients' rights and requirements; improvement of quality and instruction processes; and practice management and physical aspects of a practice. AGPAL programme has a 3-year cycle with a single on-site visit 32 .

\section{The Quality Improvement Council (QIC)}

QIC is a national non-profit organization founded in 1997 as an independent body and began operations the following year; it focuses on primary care by assisting healthcare organizations to carry out and manage quality improvement structures 412646. The QIC Standards delivered are based on a generic core module accompanied with service of specific modules aimed at attaining a great level of flexibility without duplication in services. Such Core Module deals with the organizational structure and the relationship of organization with its community with standards connected to management, planning, quality improvement, and assessment, educating and advancement, functions and its setting, patient rights and participation of patients, and community. Specific service modules deal with services such as primary healthcare, homecare, or drug and alcohol services 4639 .

\section{Canada \\ Accreditation Canada (the Canadian Council on Health Services Accreditation "CCHSA")}

CCHSA is founded following the separation of the United States and Canadian accreditation agencies in 1958. It is one of the largest worldwide accreditation programs and was the bases of the establishment of the ACHS in Australia 41. CCHSA changed its name to 'Accreditation Canada' in 2008, and currently it is the only accrediting body to offer accreditation for the entire healthcare system. It has not encountered competition from other accreditation bodies; however, it has to multiply its coverage to embrace long-term care, community services, 
organizations of mental health services, organizations of rehabilitation services, home healthcare services.

The CCHSA developed Environment standards on the safety of apparatus, materials, medical devices, and space. The CCHSA Environment module illustrates that the furniture and tools of the physical environment should be appropriate for the patient's age and level of growth. In 2010, AC introduced its International accreditation program, also attained the ISQua accreditation for standards, organization, and education programs for the fourth time 6012 .

\section{France}

The accreditation in France is mandatory and HCOs are not free to choose whether to participate in the accreditation program or not. The French accreditation has begun in 1996 upon issuing the law no. 96 of 1996 by the public government. On the reformation of public and private hospitals, and identified the necessity of creation a department to be responsible of this process, which became in 1997 the Agence Nationale d'Accréditation et d'Évaluation en Santé (ANAES). With the key aim of improving quality and safety of healthcare services, training of healthcare professionals, and providing HCOs with tools such as guidelines and approaches. Prior to the foundation of the ANAIS, there were independent and specialty-based programs (for example program for emergency services) (Fortes et al, 2011; Tabrizi et al, 2011; ISQua, 2003; Shaw, 2006). ANAES is responsible of developing accreditation program for all, public and private, HCOs in France, where its accreditation is compulsory under the law 4129 .

\section{Indonesia}

Accreditation in Indonesia started in 1995 when $\mathrm{MoH}$ created the Indonesian Commission on Accreditation of Hospitals (ICAH), as a government organization for hospital accreditation, with a program for accreditation of hospitals. The national hospital accreditation committee (KARS) was created in 1998 to administer the program. The development of the program's standards was based on the ACHS's EQuIP program, adapted to the nature of programs offered in Indonesia.

The program was voluntary and had limited credibility, with limited standards that focus primarily on input and management more than outcomes and patients satisfaction 693941.

\section{Kingdom of Saudi Arabia}

The Central Board for Accreditation of Healthcare Institutions (CBAHI)

The Central Board for Accreditation of Healthcare Institutions (CBAHI) is a non-profit agency created by the Saudi Health Council in 2001 as the official accrediting organization mandated to award accreditation certificates to all HCOs, public and private, in KSA. CBAHI's primary role is to develop and implement standards for healthcare quality and patient safety against assessment of all HCOs for proof of compliance. The creation of CBAHI dates back to 2001 as Makkah Region Quality Program (MRQP), a program aimed at improving quality of healthcare services in the Makkah Region.

In 2005, The KSA Council of Health Services (CHS) recommended the development of MRQP and was named as Central Board for Accreditation of Healthcare Institutions (CBAHI) with expanded authorization to cover the whole country. In 2006, CBAHI has developed, in cooperation with healthcare quality experts from the public and private sectors, the first edition of national standards for hospitals. In 2012, CBAHI's second series of national standards for hospitals certified by the ISQua. In late 2013, the Saudi Cabinet of Ministers mandated the CBAHI accreditation on all HCOs, also considered CBAHI accreditation as a requirement for renewal of the HCO license 1986.

The CBAHI standards concentrated on quality improvement and patient safety. The standards confirm the significance of planning; however, it did not engage patients and community leaders as partners in the process of planning 6 .

\section{South Africa}

South Africa was the first of developing countries in developing an accreditation program 74. In 1994, the faculty of medicine at the University of Stellenbosch, in collaboration with stakeholders from public and private sectors in South Africa, has created a pilot Accreditation Program for South African Health Services. In 1995, COHSASA was established as an independent non-profit agency and obtained all accreditation rights from the University of Stellenbosch 70. COHSASA adopts a method based on organization empowerment and CQI 74.

Since its establishment, COHSASA has assessed more than $600 \mathrm{HCO}$ in both the public and private sectors in 14 countries throughout the continent. COHSASA applies its accreditation 
programs in hospitals, clinics, hospices, emergency medical services, environmental health offices and rehabilitation/sub-acute facilities 70 .

\section{The United Kingdom}

There are numerous accreditation bodies in the UK, the most important of which: King's Fund Audit (KFA) and The United Kingdom Accreditation Service (UKAS): (UKAS)

The United Kingdom Accreditation Service

The UKAS is the state accreditation agency, mandated by the UK government to carry out assessment of HCOs in accordance with international standards (HQIP, 2019). In case if such international standards are not available, UKAS may apply standards developed by professional organizations, and where possible, UKAS may collaborate with professional organizations to confirm the standards contain assessment criteria that may be recognized against international standards 66 .

\section{USA}

As discussed above, the accreditation first emerged in the USA and then was implemented in Australia and Canada before it was adopted globally in the 1990s.

\section{The Joint Commission, USA}

Joint Commission (JC) on Accreditation of Healthcare Organizations is the oldest accrediting agency in the world when created in 1951 by the American Surgery Association under the name of the Joint Commission on Accreditation of Hospitals (JCAH). In 1987, the name changed to Joint Commission on Accreditation of Healthcare Organizations (JCAHO) and later to The Joint Commission 6757. Currently, the Joint Commission adopts two QMSs: CIs and patientsatisfaction indicators 206564. The JC accreditation is a voluntary program and it recommends the compliance with standards 28 . all succeeding national accreditation programmes have been based on JC standards, which primarily emphases on best practices in the $\mathrm{HCO}$ and the developing standards that aims to avoid adverse events in health care 3 .

\section{Joint Commission International (JCI)}

The JCI was launched in 1998 by JCAHO, where a group of accreditation standards was developed over a period of 16 months and was published in 2000 24. The standards contain a glossary and cross-referencing to other standards adopted for external assessment (JCAHO, Malcolm Baldrige Awards, ISO 9000 and the European Foundation for Quality Management
(EFQM)). Such standards are the foundation of JCI accreditation of HCOs around the world. They can also be used to establish and develop accreditation programs in other countries, or as an assessment tool for health ministries, public agencies and others 41. JCI mission is "to continuously improve the safety and quality of care provided to the public through the provision of health care accreditation and related services that support performance improvement in health care organizations" 9.

JCI has been accredited by ISQua. Accreditation by ISQua delivers declaration that the standards and processes adopted by JCI to review the performance of HCOs meet the best international standards for accreditation bodies 9 .

International Healthcare Accreditation Agencies

International Society for Quality in Health Care (ISQua)

The International Society for Quality in Health Care (ISQua) was established through a meeting held by EURO in Italy, to discuss the implications of quality assurance for the training of healthcare practitioners 41. ISQua is an umbrella entity for international healthcare accreditation agencies. ISQua is a small nonprofit limited company with a network of members in more than 70 countries. ISQua works to guide health sector stakeholders to deliver high level healthcare services to all people, and to continuously improve the quality and safety of care 415332.

ISQua works to standardize the development of accrediting bodies and the standards they carry out. ISQua affirms that it is necessary for accreditation standards to meet strict standards, and shall have standards for the way of developing and applying such accreditation standards 32 . (ISO)

The International Standards Organization

ISO is the leading developer and publisher of international standards applied in several sectors, including the healthcare sector 32 . In 1987, with the development of ISO:9000 'generic management system standard', ISO has grown from industrial sector into service assessment, handling particular matters in healthcare. ISO:9000 standards have been adopted as a base for assessing quality at HCOs, and due to its focus on process, with less emphasis on outcomes, ISO standards are considered to be better appropriate to technical departments in HCOs 49.

International Funding Organizations 
There are many international entities working on improvement of healthcare services. Such bodies provide technical assistance at national and international level to improve healthcare services. Such bodies including: Development banks (for example: World Bank, African Development Bank, Asian Development Bank, Inter-American Development Bank), Foreign aid programmes (Such as: The Australian Aid "AusAID", The Canadian International Development Agency "CIDA", The United States Agency for International Development "USAID"), and International nongovernmental organizations (such as: The European Society for Quality Healthcare "ESQH", The European Quality Assurance Network for Nursing "EuroQuan", International Hospital Federation "IHF", ISQua, JCI).

The policies of development banks and foreign aid agencies may significantly affect the method of structuring and operating the quality systems, particularly in developing countries. In accordance with the principles of the Alma-Ata Declaration, the key objective of such agencies is to create elementary health services and environmental safety, and not only hospitals 41 .

Overview of Jordan's Healthcare System

Jordan is a small low-middle income country with limited natural resources, with a surface area of about 89,300 square kilometers 33 , and its population in 2020 was about 10,806 million 25. The overall average life expectancy reached 72 for males and 75 for females 27 .

Jordan spends approximately $9.5 \%$ of its GDP on health services. There are many recognized healthcare providers in Jordan, but they are very fragmented. In the public sector, the Ministry of Health (MOH) manages primarily preventative medicine, but also offers specific curative services by operating numerous hospitals inside the country. The Royal Medical Service provides about $30 \%$ of health services and is highly reputable among the Jordanian citizens. The private health care sector has a huge number of visitors from several countries reflecting that it is also highly regarded. The international NGOs and other donors mainly provide its healthcare services for refugees and also operate certain teaching hospitals 23 .

Jordan's healthcare system has significantly improved during the last two decades and is ranked as one of the best health systems in the Middle East. It is a complex of three main service provision sectors: public, private, and non-profit organizations 335 . The public sector includes the
Ministry of Health (MOH), Royal Medical Services (RMS) in addition to three UniversityBased Hospitals which are Jordan University Hospital (JUH), Princess Basma Teaching Hospital (PBTH) and King Abdullah Hospital $(\mathrm{KAH})$ as well as the National Center for Diabetes, Endocrinology, and Genetics 33.

The Ministry of Health $(\mathrm{MOH})$ is the largest single provider and financier of healthcare services. Governance within the $\mathrm{MOH}$ in Jordan is extremely centralized; in contrast, it is highly fragmented and loosely regulated in the private sector 27. With regard to public health care institutions, there are 1,245 healthcare centers operated by the Jordanian Ministry of Health, 27 of these being hospitals that provide $37 \%$ of all hospital beds across the country 5 .

The private sector provides primary, secondary, and tertiary services through a network of private clinics (PCs), private centers (PCs) and private hospitals (PHs). The private sector has 59 hospitals with nearly one-third of the hospital beds in the country (4350 beds represents about $33.2 \%$ of the total beds). The majority of the hospitals, as well as private clinics, are in the capital of Jordan. The private sector contains much of the country's high-tech diagnostic capacity, and it continues to attract significant numbers of foreign patients from nearby Arab nations 335.

The international and charitable sectors provide services through UNRWA clinics for Palestinian refugees, the UNHCR, King Hussein Cancer Center and charity association clinics 3336

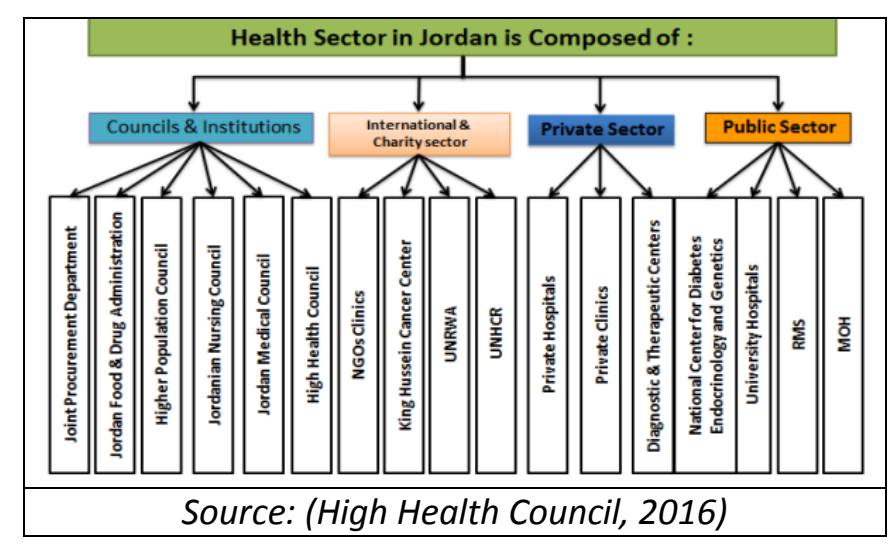

Jordan's healthcare system developing, with greater relevance to the needs of the nation, compared with most other Middle Eastern countries. It has registered numerous pioneering firsts on the regional level. It composed a staff of high professional doctors and healthcare practitioners. Jordan has quite a number of wellequipped and efficient HCOs 562. 
National health plans are reviewed pursuant the general strategic orientation and policies for most important health issues, while maintaining agreed rules and standards 73 . The Jordan's overall health policy is being made by the High Health Council (HHC). The HHC is composed by the Minister of Finance, Minister of planning and international cooperation, Minister of Social Development, Minister of labour, the director of Royal Medical Services, the president of Jordan Medical Association, Dean of one of the medical faculties replaced every two years, the president of other health-related Association appointed by the president, the president of the Private Hospitals Association and two experts from the health sector appointed by the president every two years, and headed by the Minister of Health 33.

The objective of the policies is to restructure the whole regulatory and advisory agenda of the healthcare sector as well as deliver comprehensive and efficient preventive and curative health services. This is to be done through utilizing the available resources and establishing an effective partnership with the private sector and relevant institutions 62 .

According to the Economic Policy Council 62, implementation of the policy involves improving the quality and safety of healthcare services, implementing primary healthcare programs, affiliating all public healthcare institutions with the accreditation program, and computerizing public health services through expanding and continuing implementation of the National Electronic-Health Program (Hakeem).

\section{Healthcare Accreditation in Jordan}

Jordan government understood the importance of accreditation program as an instrument for improving the quality of health services, which has become a growing main concern for the national agenda. The quality of healthcare services attains prominence among the different stakeholders and has been incorporated in the Jordan 2025 vision, the High Health Council's National Strategy for Health Sector for the year 2016-2020 and the MOH's Strategic Plan for the year 2018-2022 2336.

A national accreditation committee was formed in 1987, but its work lived short because of the lack of a governing entity that can involve all health sectors. From 1992 to 1997, the URCmanaged Quality Assurance Project (QAP) operated in the direction of introducing quality improvement committees in hospitals and creating a Quality Directorate at the MoH. In
1993, MoH has applied a quality assurance program that consists of a group of protocols and guidelines for staff in some public hospitals, and they formed committees to improve care quality in hospitals. In 1999, the MoH established the Quality Control Directorate in order to institutionalize the development of quality improvement in hospitals and healthcare centers.

This directorate is responsible for creating quality units and teams to evaluate quality and patient safety at hospitals for improving the quality of healthcare services and raise the satisfaction of both service providers and recipients at every level. In 2004, the $\mathrm{MoH}$ Quality Assurance Directorate has launched the Jordan Hospital accreditation program funded by the United States Agency for International Development (USAID) under Health Reform (PHRplus) project aiming at reforming the health sector and starting to develop a national accreditation system. In 2005, 24 hospitals were selected for participating in the pilot accreditation program in parallel with the development of Hospital Accreditation Standards.

In 2007, USAID awarded University Research Company (URC) the contract to continue the work on continuing and expanding the JHAP objectives followed by the registration of HCAC as a private non-profit shareholding company with the Ministry of Industry and Trade 3635 .

The Healthcare Accreditation Council

As above-mentioned, JHAP was launched with the goal of improving the quality and safety of healthcare services through accreditation. In order to handle the barriers faced by the Jordan's health sector, the project assisted the Government to adopt a regulatory agenda for the health sector, through the establishment of global accepted healthcare standards and accreditation 11 .

HCAC has received all three accreditation certificates from The ISQua in the areas of accreditation of standards (2007); the Accreditation of Surveyor Training Program (2009); accreditation of the Council as a grantor of certification (2013). It is the fifth agency to get the three certifications in the world, and the first in the region 3635.

The CCHSA mission is "To drive the continuous improvement of the quality and safety of health care facilities, services and programs and foster patient-centered care through developing internationally accepted standards, capacity building and awarding accreditation in 
partnership with local and regional stakeholders" 35.

HCAC has the following accreditation and certification programs (HCAC, 2020b):

- Hospital Accreditation Program.

- Primary Health Care and Family Planning Centers Accreditation Program.

- Breast Imaging Units Certification Program.

- Medical Laboratories Accreditation Program.

- Ambulatory Care Program.

- Dental Care Accreditation Program.

- Community Pharmacies Accreditation Program.

- Medical Transport Certification Program.

- Diabetes Mellitus Certification Program.

- Cardiac Care Certification Program.

- Family Planning and Reproductive Health Centers of Excellence Certification Program.

\section{Conclusion}

The literature review revealed that accreditation is considered a policy issue that gathers different countries, governmental bodies, and NGOs. Internationally, there is an abundant variety in models and structures that operate to assure quality in healthcare.

It should be noted that one of the features of USA accreditation, which formed the accreditation programs worldwide, is the voluntary nature. There are several opinions of the objectives of an accreditation program. The success of such programs is based on what is the objective of the health system that aimed at changing, pursuant to the viewpoints of those who establish the standards. Thus, countries are at different stages in the accreditation methodology. Accreditation agencies have diverse accreditation systems and diverse set of accreditation decisions.

There are countries that have long experience of accreditation as Canada, Australia, and the U.S.A, which are considered as the chief source of the accreditation development in the world. There are countries that have adopted the approach, but limiting it to their realities, as numerous countries in Europe, including France, in which the nature of accreditation evidenced to be in contradiction. Finally, there are countries that are at an early stage, as is the case in several developing countries.
Many countries have non-governmental organizations, societies, professional associations, etc., that independent, but with limited power and capacity to directly act on the health system policy decisions, promote research and provide information on the quality and/or safety of patients. However, our focus was on official agencies.

Most accrediting agencies declare ensuring healthcare quality as their primary mission, highlighting explicitly the safety of patient. Quality agencies are 'originally' dependent on the Ministry of Health, but are 'functionally' independent when exercising their mission. Actually, this was one of the inclusion criteria for the analysis. All agencies have a similar general structure, although with certain administrative and legislative particularities for each country. For most analyzed agencies, funding comes from the public budget, either directly or through the Ministry of Health.

The literature review revealed that accreditation programs have been transferred from developed countries to many developing countries, supported by a variety of international entities that work on improvement healthcare services, including Development banks, Foreign aid programs, and International NGOs.

The researcher found that accreditation programs in developing countries, where they are distinguishable from those of developed countries, are less likely to be independent, and more likely to be associated with government.

All accreditation programs have the government and public bodies as the 'key customer', based on the political structure. The differences between countries and agencies relate to the inclusion of patients/users, managers, patient or advocacy organizations, academic organizations and professional colleges.

This review has identified that the most potential comprehensive reference program or model for the development of nation accreditation programs is the JCAHO program.

\section{References}

1. ACHC. About Accreditation. 2021. Retrieved

01 15, 2021, from Accreditation Commission

for Health Care: https://www.achc.org/aboutaccreditation.html

2. ACHS. The Australian Council on Healthcare Standards Annual Report 2019 2020. NSW: ACHS, 2020. 
3. Alaradi, L., Assessing the impact of healthcare accreditation from the perspective of professionals' in primary healthcare centres: A mixed methods case study from Kuwait. PhD thesis. Scotland, UK: University of Glasgow, 2017.

4. Al-Awa, B., De Wever, A., Melot, C., \& Devreux, I., An Overview of Patient Safety and Accreditation: A Literature Review Study. Research Journal of Medical Sciences, 5(4), 200-223, 2011.

5. Algunmeeyn, A., Alrawashdeh, M., \& Alhabashneh, H., Benefits of applying for hospital accreditation: The perspective of staff, J Nurs Manag, 28, 1233-1240, 2020.

6. Alkhenizan, A., \& Shaw, C., Assessment of the accreditation standards of the Central Board for Accreditation of Healthcare Institutions in Saudi Arabia against the principles of the International Society for Quality in Health Care (ISQua). Ann Saudi Med, 30(5), 386-389, 2010.

7. Alkhenizan, A., \& Shaw, C., Impact of accreditation on the quality of healthcareservices: a systematic review of the literature. Annals of Saudi Medicine(31), 407-416, 2011.

8. Alsakkak, M., Alwahabi, S., Alsalhi, H., \& Shugdar, M., Outcome of the first Saudi Central Board for Accreditation of Healthcare Institutions (CBAHI) primary health care accreditation cycle in Saudi Arabia. Saudi Med. J., 38(11), 1132-1136, 2017.

9. Alshraideh, M., \& Abu-Arida, A., Expert system for hospitals' multi standard accreditation Jordanian study. Proceedings of the 5th WSEAS congress on Applied Computing conference, and Proceedings of the 1 st international conference on Biologically Inspired Computation, 199-205, 2012.

10. Alyahya, M., Hijazi, H., \& Harvey, H., Explaining the accreditation process from the institutional isomorphism perspective: a case study of Jordanian primary healthcare centers. The International Journal Of Health Planning and Management, 33(1): 102-120, 2016.

11. Arabji, A., Jordan Healthcare Accreditation Project Final Report: June 17, 2007 - March 17, 2013. Maryland: University Research Co., 2013.

12. Audette, S. (2015). Accreditation Canada International Defining Health Excellence. Retrieved January 17, 2021, from www.accreditation.ca: https://pdf4pro.com/cdn/accreditationcanada-international-defining-healthexcellence-3e6787.pdf

13. Bogh, S., Falstie-Jensen, A., Bartels, P., Hollnagel, E., \& Johnsen, S., Accreditation and improvement in process quality of care: a nationwide study. International Journal for Quality in Health Care, 27(5), 336-343, 2015.

14. Braithwaite, J., Greenfield, D., Westbrook, J., Pawsey, M., Westbrook, M., Gibberd, R., et al., Health service accreditation as a predictor of clinical and organisational performance: a blinded, random, stratified study. Quality and Safety in Health Care, 19(1), 14-21, 2010. 
15. Braithwaite, J., Shaw, C., Moldovan, M., Greenfield, D., Hinchcliff, R., Mumford, V., et al., Comparison of health service accreditation programs in low- and middleincome countries with those in higher income countries: a cross-sectional study. International Journal for Quality in Health Care, 24(6): 568-577, 2010.

16. Brubakk, K., Vist, G., Bukholm, G., Barach, P., \& Tjomsland, O., A systematic review of hospital accreditation: the challenges of measuring complex intervention effects. BMC Health Services Research, 15(280), 110, 2015.

17. Buetow, S., \& Wellingham, J., Accreditation of general practices: challenges and lessons. Qual Saf Health Care, 2003(12), 129-135, 2003.

18. Carrasco-Peralta, J., Herrera-Usagre, M., Reyes-Alcázar, V., \& Torres-Olivera, A., Healthcare accreditation as trigger of organizational change: The view of professionals, Journal of Healthcare Quality Research, 34(2), 59-65, 2019.

19. CBAHI. (2017). CBAHI Corporate Profile. Retrieved January 2, 2021, from https://portal.cbahi.gov.sa/Library/Assets/CB AHI\%20Corporate\%20Profile-041915.pdf

20. Chuang, S., Howley, P., \& Gonzales, S., An international systems-theoretic comparison of hospital accreditation: developing an implementation typology. International Journal for Quality in Health Care, 31(5), 371-377, 2018.

21. Cunningham, F. C., Ranmuthugala, G., Plumb, J., Georgiou, A., Westbrook, J. I., \& Braithwaite, J., Health professional networks as a vector for improving healthcare quality and safety: a systematic review. BMJ Qual Saf, 21(3), 239-249, 2011.

22. Devkaran, S., \& O'Farrell, P., The impact of hospital accreditation on qualitymeasures: an interrupted time series analysis. BMC Health Services Research, 15(137), 1-14, 2015.

23. Dick S., Improving Health Care at the National Level: Insights from the Amman, Jordan International Policy Seminar. Technical Report, Published by the USAID Health Care Improvement Project, Chevy Chase, MD: University Research Co., 2011, Retrieved from: https://www.urcchs.com/sites/default/files/jordan_policy se minar_insights_feb2011.pdf

24. Donahue, K., \& Van Ostenberg, P., Joint Commission International Accreditation: Relationship to four models evaluation. International Journal for Quality in Health Care, 12(3), 243-246, 2000.

25. DoS., Estimated population of 2020 and some of selected data, 2020, Retrieved Januaru 27, 2021, from Department of Statistics:

http://dosweb.dos.gov.jo/DataBank/Populatio n_Estimares/PopulationEstimates.pdf

26. Einfeld, S., QIC Health and Community Services Standards, 6th Ed., April 2010, retrieved January 17, 2021, from BSL library catalogue:

http://library.bsl.org.au/jspui/bitstream/1/343 6/1/QIC\%20Health\%20\&\%20Community\% 20Services\%20Standards_6th\%20ednV1\%20 2.pdf

27. El-Jardali, F., \& Fadlallah, R., A review of national policies and strategies to improve 
quality of health care and patient safety: a case study from Lebanon and Jordan. BMC Health Services Research, 17(568), 1-13, 2017 ,

28. Fortes, M., \& Baptista, T., Accreditation: tool or policy for health systems organizations? Acta Paul Enferm., 25(4), 626-631, 2012.

29. Fortes, M., De Mattos, R., \& Baptista, T., Accreditation or accreditations? A comparative study about accreditation in France, United Kingdom and Cataluña. Rev. Assoc. Med. Bras., 57(2), 234-241, 2011.

30. Greenfield, D., Lawrence, S. A., Kellner, A., Townsend, K., \& Wilkinson, A., Health service accreditation stimulating change in clinical care and human resource management processes: a study of 311 Australian hospitals. Health Policy, 123(7), 661-665, 2019.

31. Greenfield, D., Pawsey, M., \& Braithwaite, $\mathrm{J}$., What motivates professionals to engage in the accreditation of healthcare organizations? International Journal for Quality in Healthcare, 23(1): 18-14, 2011.

32. Greenfield, D., Pawsey, M., Hinchcliff, R., Moldovan, M., \& Braithwaite, J., The standard of healthcare accreditation standards: a review of empirical research underpinning their development and impact. BMC Health Services Research, 12(329): 114, 2012.

33. Hadidi, R., National Human Resources for Health Observatory Annual HRH Report 2016. Amman: High Health Council, 2017.

34. Halasa, Y., Zeng, W., Chappy, E., \& Shepard, D., Value and impact of international hospital accreditation: a case study from Jordan. Eastern Mediterranean Health Journal, 21(2): 90-99, 2015.

35. HCAC, History and background. 2020, Retrieved January 8, 2021, from Healthcare Accreditation Council: http://hcac.jo/enus/About-Us/History-and-Background

36. High Health Council, The National Strategy for Health Sector in Jordan 2016-2020. Amman: HHC, 2016.

37. Hinchcliff, R., Greenfield, D., Moldovan, M., Westbrook, J., Pawsey, M., Mumford, V., et al. Narrative synthesis of health service accreditation literature. BMJ Quality\& Safety 21(12): 979-991, 2012.

38. History.com Editors. (2020, April 21). Topics. Retrieved January 17, 2021, from History:

https://www.history.com/topics/womenshistory/florence-nightingale-1

39. Hort, K., Djasri, H., \& Utarini, A. (2013, May). Regulating the quality of health care: Lessons from hospital accreditation in Australia and Indonesia. University of Melbourne, Nossal Institute for Global Health. Health Policy and Health Finance Knowledge Hub .

40. HQIP. UK health, quality and standards organisations join forces in support of clinical service accreditation, 2019, October 22, Retrieved January 22, 2021, from https://www.hqip.org.uk/news/uk-healthquality-and-standards-organsiations-joinforces-in-support-of-clinical-serviceaccreditation/\#.YCSIYej7TIV 
41. ISQua. Quality and accreditation in health care services: a global review resulted. Geneva: WHO, 2003.

42. Jaafaripooyan, E., Agrizzi, D., \& AkbariHaghighi, F., Healthcare accreditation systems: further perspectives on performance measures. International Journal for Quality in Health Care,2011, 32(6), 645-656.

43. Jha, A., Accreditation, Quality, and Making Hospital Care Better. JAMA, 2018, 320(23), 2410-2411.

44. Lewis, J., Sanitary Commission (USSC): American Civil War Institution, 2019, February 13. Retrieved February 01, 2021, from ThoughtCo.: https://www.thoughtco.com/sanitarycommission-ussc-3528670

45. Mansour, W., Boyd, A., \& Walshe, K., The development of hospital accreditation in lowand middle-income countries: a literature review. Health Policy and Planning, 2020, 35, 684-700.

46. Matthews Pegg Consulting Pty Ltd. Standards setting and accreditation literature review and report. 2003, 166: Australian Commission for Safety and Quality in Health Care.

47. McIntosh, A., McManus, I., \& Party, C., A timeline through the ages 40 Years of ACHS History 1917-2014, 2014. Retrieved January 27, 2021, from The Australian Council of Healthcare Standards: https://www.achs.org.au/about-us/40-yearanniversary/historic-timeline/

48. Mitchell, J., Graham, I., \& Nicklin, W., The unrecognized power of health services accreditation: more than external evaluation.
International Journal for Quality in Health Care, 2020, 32(7), 445-455.

49. Montagu, D., Accreditation and other External Quality Assessment Systems for Healthcare. London: DFID Health Systems Resource Centre, 2003.

50. Ng, G., Leung, G., Johnston, J., \& Cowling, B. Factors affecting implementation of accreditation programmes and the impact of the accreditation process on quality improvement in hospitals: a SWOT analysis. Hong Kong Medical Journal, 2013, 19(5), 434-446.

51. Ruelas, E. G.-D., Leatherman, S., Fortune, T., \& Gay-Molina, J. G., Strengthening the quality agenda in health care in low- and middle-income countries: questions to consider. International Journal for Quality in Health Care, 2012, 24(6), 553-557.

52. Saut, A., Berssaneti, F., \& Moreno, M., Evaluating the impact of accreditation on Brazilian healthcare organizations: A quantitative study. International Journal for Quality in Health Care, 2017, 29(5), 713721.

53. SEHA., SEHA Annual Report 2012. Abu Dhabi : SEHA, 2012.

54. Shaw, C., Accreditation in European Health Care. Joint Commission Journal on Quality and Patient Safety, 2006, 32(5), 266-275.

55. Shaw, C., Accreditation is not a stand-alone solution. Eastern Mediterranean Health Journal, 2015, 21, 226-231.

56. Shaw, C., Groene, O., Botje, D., Sunol, R., Kutryba, B., Klazinga, N., et al., The effect of certification and accreditation on quality management in 4 clinical services in 73 
European hospitals. International Journal for Quality in Health Care, 2014, 26(S), 100107.

57. Sheingold, B., \& Hahn, J., The history of healthcare quality: The first 100 years 1860 1960. International Journal of Africa Nursing Sciences, 2014, 1, 18-22.

58. Shell, C., \& Dunlap, K., Florence Nightingale, Dr. Ernest Codman, American College of Surgeons Hospital Standardization Committee, and The Joint Commission: Four Pillars in the Foundation of Patient Safety. Perioperative Nursing Clinics, 2008, 3, 19-26.

59. Swiers, R., \& Haddock, R., Assessing the value of accreditation to health systems and organisations. Evidence Breif No. 12. Deeble Institute for Health Policy Research, (2019, May 10).

60. Tabrizi, J., Gharibi, F., \& Wilson, A., Advantages and Disadvantages of Health Care Accreditation Models. Health Promotion Perspectives, 2011, 1(1), 1-31.

61. Tehewy, A., Salem, B., Habil, I., \& El Okda, S., Evaluation of accreditation program in non-governmental organizations' health units in Egypt: short-term outcomes. International Journal for Quality in Health Care, 2009, 21(3), 183-189.

62. The Economic Policy Council. JORDAN ECONOMIC GROWTH PLAN 2018 - 2022. www.egp.jo.

63. The Joint Commission International. Accreditation, 2021. Retrieved January 17, 2021, from The Joint Commission: https://www.jointcommissioninternational.or g/accreditation/accreditation-programs/
64. The Joint Commission. Specifications Manual for Joint Commission National Quality Measures, 2014. Retrieved Januray 10 , 2021 , from: https://manual.jointcommission.org/releases/ TJC2014A1/TransmissionChapterTJC.html\# Overview

65. The Joint Committee, The Joint Commission: Over a century of quality and safety, 2020. Retrieved January 10, 2021, from https://www.jointcommission.org//media/tjc/documents/about-us/tjc-historytimeline-through-2020.pdf

66. UKAS. UKAS Accreditation: A briefing for Commissioners of Healthcare Services, 2016. Retrieved January 22, 2021, from UKAS: https://www.ukas.com/wpcontent/uploads/filebase/brochures/B11\%200 3_2016\%20V2\%20Commissioners\%20Broc hure.pdf

67. Viswanathan, H., \& Salmon, J., Accrediting Organizations and Quality Improvement. The American Journal of Managed Care, 2000; 6(10): 1117-1130.

68. Waide, S., Delmage, E., Haley, M., Lapinski, J., \& Rothstein, J., The United States Sanitary Commission Records (1861-1879), 2013. Retrieved January 12, 2021, from The New York Public Library - Manuscripts and Archives Division: http://archives.nypl.org/uploads/collection/ge nerated_finding_aids/mss3101.pdf

69. Wardhani, V., Van Dijk, J., \& Utarini, A., Hospitals accreditation status in Indonesia: associated with hospital characteristics, market competition intensity, and hospital 
performance? BMC Health Services Research, 2019; 19(327): 1-10.

70. Whittaker, S., Green-Thompson, R., Mccusker, I., \& Neymbezi, B., Status of Health Care Quality Review Programme in South Africa. International Journal for Quality in Health Care, 2000; 12(3): 247250.

71. WHO, OECD, \& The World Bank., Delivering quality health services: a global imperative for universal health coverage. Geneva, 2018.

72. WHO. Quality improvement in primary health care: a practical guide. 2004. (A. AlAssaf, \& M. Sheikh, Eds.) Retrieved January
02, 2021, from WHO Regional Office for the Eastern Mediterranean: https://applications.emro.who.int/dsaf/dsa231 . $\mathrm{pdf}$

73. WHO. Jordan health profile 2015. Cairo: WHO Regional Office for the Eastern Mediterranean, 2017.

74. Zeribi, K., \& Marquez, L., Approaches to Healthcare Quality Regulation in Latin America and the Caribbean: Regional Experiences and Challenges. LACHSR Report Number 68. Published for the U.S. Agency for International Development (USAID) by the Quality Assurance Project. 


\title{
تطوير أنظمة اعثماد الرعايةة الصحية من العالمية إلى المحلية \\ فاتن سليمان صالح

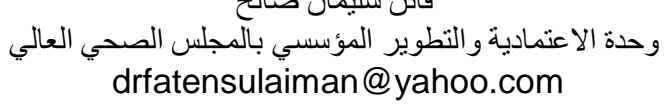

\author{
2021/6/27: قبول البحث \\ 2020/12/23: استلام البحث
}

الملخص

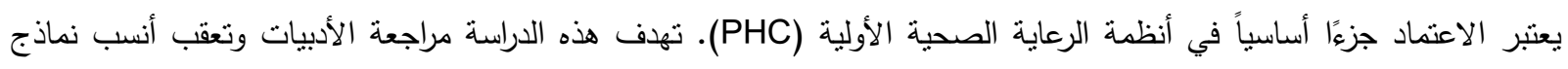

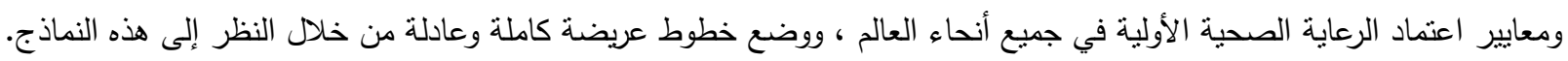

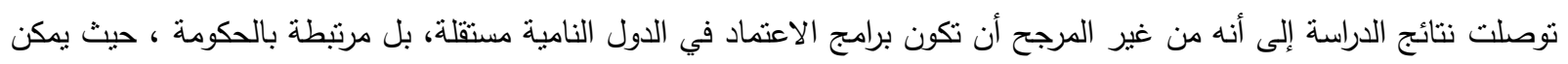

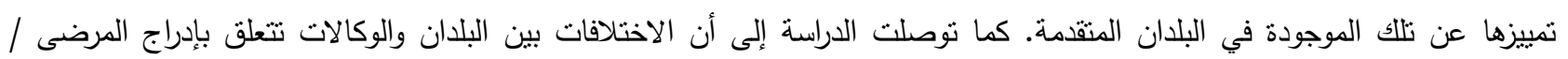

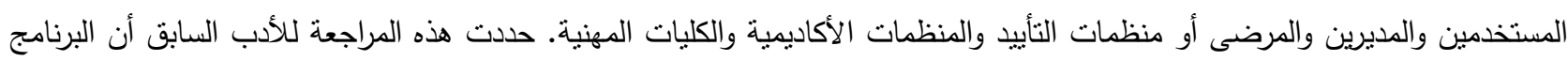

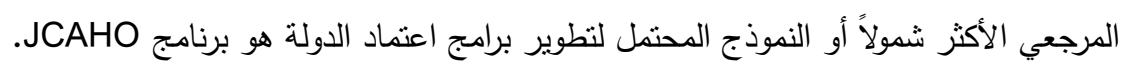

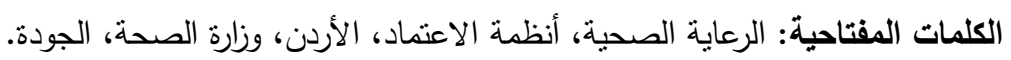

